\title{
ФОРМИРОВАНИЕ НАУЧНОГО СТИЛЯ НА ТУРЕЦКОМ И АЗЕРБАЙДЖАНСКОМ ЯЗЫКАХ В XIV-XVI ВЕКАХ
}

\section{FORMATION OF SCIENTIFIC STYLE IN TURKISH AND AZERBAIJAN LANGUAGES IN XIV-XVI CENTURIES}

\section{Sh. Hasanli-Garibova}

Summary: This article comprehensively discusses the issue of the formation and standardization of the scientific style in the Turkish and Azerbaijani languages. Normalization is studied both in general terms and from the point of view of its internal development. Particular attention is paid to the properties and reasons influencing the process of the formation of a scientific style, stylistic aspects of standardization are considered. The novelty of the research lies in the consideration of the development process of the scientific style, taking into account the characteristics of its sub-styles. The merit of the author is the proof that the history of the formation of the scientific style of the Turkic languages dates back to the XIV century. The relevance of the study is due to the need to determine the time frame for the formation of the scientific style in the Turkic languages. The work provides definitions of such concepts as normalization, standardization, functional styles, scientific style, artistic style, etc. The author dwells on the issues of differences in the phonetic, lexical and grammatical layers of the Turkic languages. The presence of micro-styles in the Azerbaijani and Turkish written monuments has been proven. The author reviewed the available scientific concepts and scientific literature on this topic. The article is a fragment of the author's long-term research in the field of the history of the functional stylistics of the Turkic languages - in general, and the Azerbaijani language - in particular.

Keywords: term, scientific style, Turkic languages, language norm, lexical norm, substyle, Turkish language, Azerbaijani language, normalization, functional styles.
Гасанлы-Гарибова Шабнам Расим кызы

Д.философии по филологическим наукам, доцент, Институт Языкознания имени И. Насими Национальной Академии Наук Азербайджана (2. Баку) hasanli-qaribova@mail.ru

Аннотация: В настоящей статье всесторонне рассматривается вопрос формирования и стандартизации научного стиля в турецком и азербайджанском языках. Нормализация изучается как в общих чертах, так и с точки зрения его внутреннего развития. Особое внимание уделяется свойствам и причинам, влияющим на процесс формирования научного стиля, рассматриваются стилистические аспекты стандартизации. Новизна исследования заключается в рассмотрении процесса развития научного стиля с учетом характеристик его подстилей. Заслугой автора является доказательство того, что история формирования научного стиля тюркских языков восходит к XIV веку. Актуальность исследования обусловлена необходимостью определения временные рамки становления научного стиля в тюркских языках. В работе приводятся определения таких понятий как нормализация, стандартизация, функциональные стили, научный стиль, художественный стиль и др. Автор останавливается на вопросах различий в фонетическом, лексическом и грамматическом пластах тюркских языков. Доказано наличие микро-стилей в азербайджанских и турецких памятниках письменности. Автором выполнен обзор имеющихся научных концепций и научной литературы по данной теме. Статья является фрагментом многолетнего исследования автора в области истории функциональной стилистики тюркских языков - в целом, и азербайджанского языка - в частности.

Ключевые слова: термин, научный стиль, тюркские языки, языковая норма, лексическая норма, подстиль, турецкий язык, азербайджанский язык, нормализация, функциональные стили.

\section{BBEAEHИE}

$\mathrm{O}$ бзор начального этапа формирования научного стиля в языках мира, позволяет стать свидетелем одной и той же картины: ведущим в таких произведениях является описательный характер, наблюдается незначительное отличие от авторского языка, преобладают простые объяснения и высказывания фантастических идей. Рассмотрим отрывок из произведения «Хуласа» турецкого писателя XIV века X. Бараката: "Muhammed Zekeriye Rahmetullahi Eydur ol burhan ki, ISSI sayrulıklarda ola sersem ve birsam gibi kuvvetlu ısıtmalar ve kuru sayrulıklar gibi dördüncü gün düşvar gündür, sekkizinci gün muhataradur ve on ikinci gün dahi beterdür yigirmi günendegin ve artuk varmaz çün yigirmiden geçe selim ola"
[1, с. 25]. Приведенная цитата позволяет сделать вывод, что информация о заболевании, передающемся путем заражения, написана в стиле, близком к описательному стилю турецкого языка той эпохи.

Т. Гаджиев пишет: «Стиль в литературном языке - это комплекс материалов литературного языка, отношение языковой единицы к значению и форме, отношение с ней, а также система способов анализа, осмысления и направления фактов речи» [2, с. 246]. Стиль, как выражение определенного образа мышления, наделен специфическим характером в составе литературного языка. Его развитие дает толчок развитию литературного языка в новом русле. «В определенном смысле история литературного языка охватывает и историю разных стилей. 
В свою очередь, история стиля также более или менее отражает особенности развития литературного языка на конкретном этапе. Стиль как историческая категория органически связан с историей развития народа [3, c. 9]. Таким образом, стили тесно связаны с развитием и нормализацией литературного языка как основные исторические категории литературного языка. Стили, непосредственно относящиеся ко всем разделам языковой системы, являются основным критерием измерения уровня развития всех языковых пластов.

История научного стиля в мировом языкознании весьма разнообразна. С древних времен греческий, а затем и латынь были международными «научными языками» всей Западной Европы. На Востоке подобный статус имел арабский язык. Если приобретение латинским языком этого статуса было связано с его древним «аристократическим положением», то превращение арабского языка в доминирующий язык носил сугубо политический и культурный характер. Об этом М. Мaхмудов пишет: «Для укрепления своей власти на оккупированных территориях арабы использовали ислам в качестве мощного идеологического инструмента. Арабы проводили политику насильственной исламизации, они безжалостно уничтожали древнюю культуру тех народов, внедряли в их умы новую религию». В результате арабский язык становится доминирующим и за короткое время превращается в основное средство общения между разными народами. Все произведения создаются и распространяются на этом языке, благодаря ему приобретают общемусульманский характер» [4, с. 5].

С одной стороны, это было удобно, поскольку была создана единая научная среда. Независимо от национальности и родного языка, ученые различных областей науки могли читать работы своих коллег, живущих рядом или далеко, и были в курсе последних научных достижений. С другой же стороны, в некоторых странах замедлялось формирование национальной научной среды и развитие научной базы национального языка. В результате статус латинского и арабского языков как «международных научных языков» был утерян, а их место заняли работы, написанные на национальном языке с учетом национального образа мышления.

Таким образом, хотя идея создания национальной научной среды в Европе стала озвучиваться еще в XVII веке, но доминирование тюркского языка на Востоке в XIII веке завершилось тем, что на Ближнем Востоке он вытеснил использование арабского языка в научном стиле. Это, конечно, было связано с прямым влиянием социально-политических условий. Однако понятие турецкого языка носило символический характер. Так, в XIII веке концепция единого турецкого языка давно исчезла, и сформировались разные литературные языки: османский-анатолийский турецкий, азербайджанский турецкий и чагатайский турецкий.

Говоря о тюркских литературных языках XIII-XIV веков, Г. Багиров, выдвигает несколько иную гипотезу: «Рассуждая о периоде среднетюркского литературного языка (XIII-XV вв.), тюркологи говорят о существовании двух литературных языков. Речь об имеющих самостоятельную литературную языковую традицию среднеазиатских тюркских и волго-уральских тюркских языках. Нельзя отрицать существование третьей группы памятников, которую мы условно называем ближневосточной группой. Эта группа памятников отличается от золотоордынской и среднеазиатской языковых групп [5, с. 40-41]. В рамках ближневосточной языковых групп, автор выделяет анатолийский и азербайджанский тюркские ветви и указывает на конец XIII века как дату полностью сформировавшегося литературного азербайджанского языка.

А. Демирчизаде, ссылаясь на лингвистические факты «Дивану-лугат-ит-тюрк» М. Кашгарлы, утверждает, что азербайджанский язык сформировался еще в XI веке: «Информацию и объяснение об огузском и кыпчакском языках, которую дал М. Кашгарлы, следует рассматривать как принадлежность к новому языку тюркской системы, который был вновь сформирован в XI веке, т.е. к азербайджанскому языку [6, с. 129].

Изучая историю литературного языка, Т. Гаджиев различает его устный и письменный этапы. Ученый приходит к следующему выводу: «Из всего этого можно заключить, что письменный литературный тюркский азербайджанский язык существовал за двести лет до XIII века, т.е. еще в XI-XII веках» [7, с. 95].

Существование письменного литературного языка указывает на сложившуюся систему стилей. Отметим, что в исследованиях по истории литературных языков, как в азербайджанском языкознании - в частности, так и в тюркологии - в целом, в первую очередь в качестве источников широко анализировали творчество И. Насими, Г. Бурханеддина, М.К. Руми, М. Фузули, С.И. Хатаи и других авторов, создавших уникальные образцы художественного стиля. Создается впечатление, что научный и другие стили языка в тот период не сформировались. Изучая историю развития стилистики азербайджанского языка, Т. Эфендиева руководствуется следующим принципом и пишет: «На основе устного фольклорного стиля формируется художественный стиль литературного языка. Долгое время наш литературный язык был вынужден развиваться и становиться через этот стиль. Поэтому каждый этап развития нашего литературного языка в той или иной степени связан с именами известных личностей» [8, с. 30].

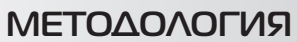

В целом, подходы лингвистов к вопросам стилистики 
средневековых тюркских языков несколько различаются. Так, подавляющее большинство исследователей выделяет два стиля литературного языка: классический и народный. «В начале (в основном, на стадии формирования) стилистическая дифференциация языков не была четко выражена. Позже эволюционный процесс постепенно стал приобретать определенные черты, чему способствовали формирующиеся классический и народнолитературный стили» [9, с. 41].

Т. Эфендиева соглашается с мнением историков азербайджанского языка о существовании двух стилей в период его становления с VIII-X вв. до XVII в. Т. Эфендиева различает классический книжный и разговорно-народный стили. «...C конца XVI в. до начала XVI в. классический стиль литературного языка все больше обретает определенность и играет ведущую роль. На этом этапе, благодаря философским стихам Насими, в языке поэзии стали закладываться первые краеугольные камни научного стиля. Начался процесс деления функционального стиля» [8, с. 32]. С некоторым сомнением можно говорить о том, что философские идеи в средневековой турецкой поэзии были первыми зародышами научного стиля. Однако тот факт, что первые научные книги и словари были написаны в стихах, дает основание утверждать, что научный стиль отделился от художественного. На самом деле обращение к поэзии связано с первыми научными пособиями, которыми были учебники, а система обучения в школах того времени была основана на методе зазубривания. Например, труд «Мунтахаб-Шифа» Джалалуддина Хизира, который жил во второй половине XIV - начале XV веков, был написан по совету старшего преподавателя и главного врача медицинского училища Сабунджуоглу Шерафеддина. Этот труд был переработан Мухиддином Мекки. Для удобства зазубривания текста он трансформировал прозаический текст в стихотворный и дал ему сокращенное название «Тахсил» [10, с. 5]. Фактически, использование поэтического изложения в качестве средства выражения в научном стиле открыло путь для проникновения особенностей художественного стиля в научный.

Как видно, историческое становление и развитие научного стиля несколько отличается от других стилей тюркских языков. Так, научный стиль, сформировавшийся позже художественного, долгое время развивался на основе других языков. В результате лексическая база научного стиля турецких языков пополнилась словами, заимствованными из других языков. Однако с конца XIII века изменения в социально-политической ситуации, относительная стабильность региона и забота тюркских государств о языке, а также использование турецкого языка в медресе привели к формированию научного стиля на родном языке.

\section{Роль словарей и перевода в формировании научного стиля}

Следует отметить, что турецкий язык впервые появился в словарях и в лексико-грамматических трудах как второй язык. Постепенно он превратился в основной язык для выражения научных идей. С целью обучения персидскому языку в Анатолии были созданы персидско-турецкие словари. В то же время, для изучения турецкого языка и его диалектов в Иране, Азербайджане, Индии и других регионах были написаны турецко-персидские словари [11, с. 47]. Первый турецкий словарь был составлен Фахраддином Мухаммадом ибн Мустафа ибн Захария, жившим в XIII веке в Анатолии. Это труд «Кава`иду Лисани`т-тюрк» Гасана Салгури. До наших дней не сохранилось ни одного экземпляра этого произведения, написанного в поэтическом жанре. Первым словарем того периода был «Тёхфейи-Хуссам» Хусамеддина Хоя, написанный в стихотворной форме на азербайджанском языке.

Позже научные работы, написанные на других языках, были заменены переводами тюркоязычных авторов на турецком языке. Однако эти произведения не переводились дословно, а были переработаны на основе оригинального текста, расширены дополнениями и носили характер комментариев. «В целом, при оценке средневековых следует отбросить критерии и оценки современных переводов, и в то время, когда эти работы появились. За основу должны браться индивидуальные особенности переводов, соответствующие эпохе их создания. В этом случае следует принять во внимание и оценить такие вопросы как: степень близости переводного произведения к оригиналу; было ли это произведение в средние века признано переводом или оригиналом; под каким названием (перевод или оригинал) оно было более известно в ту эпоху» $[12$, с. 16].

Следует признать, что перевод дал толчок развитию не только художественного, но и научного стилей. Написанные на арабском языке сочинения Х. Тифлисского, $\mathrm{H}$. Туси и др. мыслителей в предыдущих веках, были переведены на турецкий язык. Первые оригинальные научные труды, написанные в конце XIV века на турецком языке, отражали в себе языковые нормы того времени. В этих работах в различных формах отражаются и нормативные изменения. Чаще всего наблюдаются определенные изменения в развитии нормы и тенденции к ее защите.

\section{Основные условия формирования научного стиля} в тюркских языках

Следующие условия способствовали формированию на национальной почве научного стиля в тюркских языках:

1. Осуществление на территории Азербайджана в государствах Гарагоюнлу, Аггоюнлу, Сефевидов, в 
Османской империи в Анатолии, в правительстве Хусейна Байгара в Герате политической деятельности на родных языках.

2. Приобретение азербайджанским языком статуса официального языка в государстве Сефевидов.

3. Создание в Герате Алишером Наваи непревзойденных образцов письменности на турецком языке.

4. Превращение турецкого языка в мировой язык в результате завоеваний османских султанов.

«Экономический и политический рост превращает Азербайджан в ведущую научную и культурную страну Востока. В XV веке на весь Восток прославились работы С.А. Ширвани в области философии, а также А. Бакуви в области истории и географии. Воспитанник азербайджанской культуры XV века, великий музыковед, уникальный мастер удовой музыки Абдулгадир Мараги является автором трудов по восточной музыке и ее стилям, которые до сих пор используются в качестве учебников в известных музыкальных школах» [2, с. 231]. В результате в число источников литературного языка наряду с образцами художественного стиля, вошли и труды по медицине, астрономии, лингвистике, теории литературы, юриспруденции, шариату и т.п. Также были написаны ценные труды и научные трактаты. В этот период созданы трактаты Абри Гадже ибн Адиля «Ихтиярати каваидикуллия», произведения Камала Умми Исмаила Караманли «Дивани- Илахиййат» (1475-1476 гг.), Мовланы Ахмада аль-Бардаи «Хашия-ал Бардайи ала шарх ал-каваид ан-нафсийя-Тафтазани» (XVв.), М.Биркили «Ан- дурр-ал йетим фи-илм ат-таджвид» (XVI в.), два труда шейха Исхака Ризайи Занджани «Манзумеи- агаид» и «Назмулулум» (XVI в.); переводы с оригинала труда Насреддина Туси «Ахлаги -Насир», сделанный Али ибн Хусайном аль-Амаси «Таджул-адаб» (XV в.), с оригинала «Кимяйисаадат», осуществленный Сахабином Газали «Тадбирииксир» (XVI в.), с оригинала X. Тифлиси «Камилут-табир», сделанный Бавазичи «Кавамилут-табир» (XVI в.) и т.п.

Эти произведения полностью раскрывают возможности тюркских языков выражать научные идеи и достижения того времени. «Известно, что история развития литературного языка связана, с одной стороны, со структурными изменениями на разных уровнях языка, а, с другой - с особенностями стилистической дифференциации литературного языка в конкретный исторический период» [3, с. 6].

\section{Стандартизашия в тюркских языках и его отраукение в научном стиле}

B XIII-XVI веках развитие тюркских языков, в том числе азербайджанского литературного языка, проходит на сложной логической структуре, в отдельных направлениях прослеживаются особенности. Таким образом, на- ряду с усилением позиций классического стиля наблюдается максимальная стандартизация литературного языка. В прозаических произведениях, особенно в научном стиле, привлекает внимание простота и беглость разговорного языка. XIII-XVI века - это период, когда на тюркских языках и в художественном, и в научном стилях были написаны классические и трудные для понимания произведения. Однако в этот период на языке, близком к народному языку, писали и книги по медицине, астрономии, лингвистике и др. Большое количество рукописей того периода и достаточное количество среди них образцов научного стиля представляется важным с точки зрения отслеживания эволюции стилистической дифференциации и нормализации языков. Тот факт, что ведущие функциональные стили (например, системы художественного и научного изложения) кажутся «противопоставленными» системе выражения, не говорит в пользу формирования литературного языка. В этом случае в XI-XIII веках в период формирования письменного азербайджанского литературного языка, возможно и в синкретической форме, но уже существовала дифференциация стилей. «K XIV-XV векам относятся зрелые образцы художественного стиля разных форм поэзии, характерные для той эпохи. Налицо усиливающийся процесс становления научно-философского стиля. Возникают элементы религиозно-пропагандистского (общественно-политического) стиля» [9, с. 95].

Этот этап также является этапом относительного размежевания общевосточного художественного и научного мышления, этапом национализации в разных стилях универсальных арабо-персидских моделей. Так, начавшаяся C XIII века наблюдаемая попытка отдельных авторов писать произведениях на родном языке, получила широкое распространение к концу XIV века. В результате, наряду с новыми произведениями на турецком языке, появляются турецкие переводы на арабский и персидский языки более ранних произведений. Этот процесс заложил основу для упрощения письменной речи. Научные работы того периода являются одними из наиболее заметных источников такого упрощения. В большинстве таких примеров, напоминающих обычную разговорную речь, определительных словосочетаний больше чем изафетных конструкций; простых предложений больше, чем сложных. За счет союза «и» и пояснительных слов образуется последовательный ряд простых предложений, а вся тяжесть информации ложится на грамматическую основу предложения - подлежащее и сказуемое.

В истории развития литературного языка научные труды, составляющие основу научного стиля, появились на том этапе, когда поэты и ученые подходили к научным вопросам с национальной точки зрения и писали научные труды на родном языке. В XIII-XIV веках расширение сфер употребления азербайджанского-турецкого 
языка привело к увеличению количества двуязычных и трехязычных толковых словарей и появлению новых переводных произведений. В османской языковой среде появились труды Мурада бин Исхака «Эдвиеи-Муфрада», «Ад-дурратул-мудиййе фил-лугатит-Туркиййа» (XIV в.), Кадри Бергамалийского «Муяссиретул-улум» (XVв.), Пири Раиса «Китаби- Бахрия» (XV в.), Сабунджуоглу Шарафаддина «Джеррахнамейи-Илхан», «Муджерребнаме» (XV в.), Ашик Пашазаде «Теварихи- Али-Осман» (XVв.), Хакима Бараката «Хуласа» (XIV в.), Махмуд Ширвани «Илясиййе», «Джевхернаме», «Тухфеи-Муради», «Терджумеи-Китабут-Табих», «Султаниййе», «Китаби-ГузидеиИлми-Тибб», «Муршид» (XVв.), Такиуддина «АлатиРасадиййе».

Очевидно, что история научного стиля в тюркских языках восходит к XIV, а не XVIII-XIX векам. Историческая основа научного стиля тюркских языках связана с трудами турецких ученых и мыслителей, творивших на арабском и персидском языках.

\section{Нормативизашия в тюркских языках и ее отражение в научном стиле}

Нормативизация языка и следующие из нее различия тесно связаны с активностью употребления языка в данном его направлении. Дворцовый язык Сефевидов XVI века считается отправной точкой возникновения официального стиля азербайджанского языка. Однако в последующие периоды в этой области наблюдается восстановление власти персидского языка, место которого позднее занял русский язык. Таким образом в «архетипе» азербайджанского языка официальный стиль не способствовал становлению процесса нормативизации языка. Однако, если обратиться к турецкому языку, то и сегодня в турецкой официальной речи можно видеть использование некоторых архаичных слов, присущих разговорному языку времен Османской империи. Эти слова продолжают оставаться нормой официального языка. Например, местоимение «іşbu» (ишбу) сохраняет свою функцию в языке официальных документов, однако при этом в повседневной речи оно используется достаточно редко. Заметим также, что в азербайджанском языке данное местоимение полностью архаизировалось. Если обратиться к архивам Парламента Азербайджанской Демократической Республики, относящимся к 1918 году, то можно видеть употребляемость данного местоимения, например: "İşbu qanun qabul edildiyi gündən icra edilsin" [13, c. 176] (Настоящий закон подлежит исполнению со дня его принятия), "Natiqlardən bir çoxları işbu masəlanin çarəsi haqqında sabablar göstardilar ki..." [13, с. 219] (Многие из спикеров назвали причины решения этого вопроса) и т.д.

Со временем по тем или иным причинам норма может потерять нормативность и изменить свою функциональность. Данное положение верно для большинства лексических норм. Таким образом, стабильность грамматических норм тюркских языков обеспечивается их агглютинативностью. В целом, изменения грамматических норм происходят в результате долгой эволюции и в довольно редких ситуациях. Например, в турецком языке суффикс "-yor" не был почти замечен до XVI века, однако в турецком языке XXI века он стал нормативным аффиксом настоящего времени. Говоря об употреблении аффиксов "-yor, -yür" в Орхоно-Енисейских памятниках XI-XII веков, Ш. Шукуров приводит в качестве подтверждения примеры использование таких слов как "başlayur" (начинается), "sözlayür" (говорится) [14, с. 177]. В приведенных примерах согласный “u” (у) не принадлежит аффиксу, он является соединительным согласным между корнем слова и аффиксом. Ш. Шукуров отмечает, что в словах, оканчивающихся на гласную, в XIII-XV веках аффиксы р и "-yur/-yür" употреблялись параллельно и дополняет свое мнение примерами "Ne tileyürsen?" и "Ne tilersən?" (что ты хочешь?) из «Рабкузи» 14, с. 177].

К примеру, аффиксы "-r" и "-Ir", которые в XIV-XVI веках использовались в качестве показателей перифрастической формы глагола, широко употребляются и в современном турецком языке. Однако верно и то, что встречающееся в образцах письменности XVI века употребление аффикса "-ir"', указывающего на перифрастическую форму глагола, не носило характера нормы. С другой стороны, для средневекового османского языка замена огубленной гласной в вариативном аффиксе -ır на неогубленную являлось нормой, например, "Her birisinün kapusunda yazılmışdur... Evvelki kapu sevmerdleründür. Ikinci kapu namaz kılanlarundur" (XIV в.) [15, с. 125] (На каждом из дверей был надпись... Первая дверь для влюбленных. Вторая дверь для тех, кто молится). В современном турецком языке нет речи о нарушении закона слоговой гармонии в аффиксе в позиции конца слова.

В целом, в тот период сложилась ситуация, когда перестановки в аффиксах приобрели традиционный характер, т.е. к словам, оканчивающимся в аффиксах на губную гласную, добавлялись неогубленные гласные; а к словам, оканчивающимся на неогубленную - добавлялась огубленная: "Sultan Muhammede getürdi. Axşamın çadırda maslahat neyise gördiler, yirine kodılar. Ol gice Bursaya dedesi yanına göndürdiler" [16, с. 356] (Пришли к Султану Мухаммеду. Вечером в шатре решили все, что надо, все поставили на свои места. В ту же ночь отправили его к деду в Бурсу). "Bu maruzun ilacı dahı bir-birine yakundur" [10, c. 129] (Лекарства от этих болезней схожи).

Этот процесс также отражен в примерах, взятых из чагатайских памятников того периода. Следующие примеры из произведения «Мизанул-евзан» Алишера Навои показывают, что в XV веке этот процесс для всех тюркских языков носил характер нормы: "tüzdi" (положил по 
порядку), "görgüzdi" (показал), "rast kiltürdi" (встретил), "meded yitkürdi" (умолял о прощении) [17, с. 11] и т.д.

Н. Джафаров, исследовавший историческое нарушение сингармонизма в XVIII веке, пишет, что «... в процессе формирования национальной нормы складываются такие условия, при которых западная и восточная культуры произношения могли вступать в оппозицию с весьма принципиальной установкой: Восток опирается на стабильные письменные традиции, Запад - на устную речь, в результате диалектическая оппозиция в отношениях «сохранения-утраты» губной гармонии, в действительности, оказывается синхронизированной» [18, с. 56].

В произведениях Навои вспомогательный глагол "irmiş" встречается довольно часто, например: “...сӥn arab irmiş ve anın yakınında bir vadi irmiş, ve anı Aruz dirler irmiş" [17, с. 13] (... они были арабами и рядом с ними была долина, которая называлась Аруз). А в принадлежащем к XVI веку произведении «Муйессиретул-улум» вместо "irmiş" используется вариант "imiş": "Pes ma'lum oldı ki, harf icun bizzat ma'na yok imiş, bir axar kelimeye koşılmaylnca ma'na hasil olmaz imiş" [19, c. 7] (Стало известно, что буква не имеет никакого смысла, оно обретает смысл в слове). Сочетания, образованные при помощи вспомогательного глагола "imiş" Кадри Бергамалийский называет "хикаети-халиййеи-тешкикиййе" [19, с. 14], что в переводе означает повествовательная форма прошедшего времени. Частица "-ermiş/irmiş" является древней формой частотной в современном языке частицы "-imiş". Х. Мирзазаде считал "erdi / irdi", "ermiş / irmiş" однокоренными вспомогательными глаголами: «Со временем звук [r] в составе слова ослаб и выпал, в итоге в современном

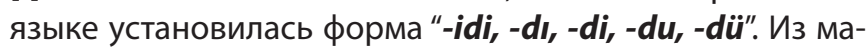
териалов азербайджанского языка становится ясно, что начальный компонент этого слова "-er/-ir" представляет собой остаток самостоятельного глагола "irişmek" [20, с. 220]. Из произведения М. Кашкарлы следует, что корнем слова был "er". Приведем примеры: "Qanda erdin?" (Где ты был?) [21, с. 418], "Ol andağ erdi" (Это было так) [21, c. 164]. "Ol menin birle erdi" (Он был со мной) [21, с. 430]. Корнем слова был глагол "er" в значении «быть», «существовать». Исторически сложилось так, что в результате падения буква "r" от слова "er", сформировался глагол, состоящий из одного звука "e /i(mek)". Представленный в рамках определенных форм глагол "er" в определенных позициях постепенно замещался вспомогательными глаголами "ol / bol" и "dur / tur".

\section{выво $\Delta$ ы}

И так, если обратиться к истории развития нормализации функциональных стилей в тюркских языках, то можно видеть, что в средние века нормализация научного стиля прослеживается в двух направлениях:

1. Согласно поэтапно общей нормализации тюркских языков.

2. Согласно нормализации собственного научного стиля в каждом из тюркских языков.

Общая нормализация - это основная отличительная особенность языков.

Внутренняя нормализация языка происходит на фонетическом, морфологическом, лексическом уровнях языка и различается на определенных его этапах.

Упрощение, ослабление с последующей заменой одного языкового явления другим, обычно происходят на основе требований речи и регулируются внутренними законами этого языка.

Основным признаком нормализации собственного научного стиля всех отраслей наук является большое влияние разговорной речи, особенно в области медицины. В научных трудах по религии наблюдается утяжеление классического стиля.

Исторически нормализация охватывает все сферы языка, между которыми существует диалектическая связь. Общие языковые нормы, в свою очередь, различаются в рамках функциональных стилей языка, что обеспечивает специфику функционального стиля и позволяет выражать внутреннюю норму языка. Присущая научному стилю терминология, отсутствие эмоциональности, схоластическая структура предложений являются основными показателями нормы.

\section{ЛИТЕРАТУРА}

1. Bereket H. Hulasa. Ankara: TDK, 2016. 623 s. [на турецком языке].

2. Hacıyev T. Azərbaycan ədəbi dilinin tarixi [I cild]. Bakı: Elm, 2012. 476 s. [на азербайджанском языке].

3. Adilov V. XIX әsr Azərbaycan ədəbi dilinin elmi üslubu. Bakı: Nurlan, 2002. 136 s. [на азербайджанском языке].

4. Mahmudov M. Әrəbcə yazmış azərbaycanlı şair və ədiblər. (VII-XII әsrlər).Bakı: Şərq-Qərb, 2006. 192 s. [на азербайджанском языке].

5. Bağırov Q. Ümumxalq dilinin formalaşmasına və təşəkkülünə dair / Q. Bağırov // Azərbaycan dilçiliyi müntəxabatı, Il cild, Bakı: Prestige, 2013. 438 s. [на aзepбайджанском языке].

6. Dəmirçizadə Ә. Azərbaycan dili oğuz qrupuna mənsub dillərdəndir: [Azərbaycan dilçiliyi müntəxabatı], Il cild, Bakı: Prestige, 2013. 438 s. [на азербайджанском языке]. 
7. Hacıyev T. Seçilmiş әsərləri. I cild, I hissə. Bakı: Elm, 2016. 496 s. [на азербайджанском языке].

8. Әfəndiyeva T. Azərbaycan ədəbi dilinin üslubiyyat problemləri. Bakı: Nurlan, 2017. 184 s. [на азербайджанском языке].

9. Cahangirov M. Milli təşəkkül mərhələsində Azərbaycan ədəbi dilinin aparıı üslubları. Bakı: Elm, 1989. 280 s. [на азербайджанском языке].

10. Hızır C. Muntahab-ı Şifa. Ankara:TDK, 1990. 223 s. [на турецком языке].

11. Öz Y. Tarih boyunca Farsça-Türkçe sözlükler. Ankara: TDK, 2010. 360 s. [на турецком языке].

12. Nağısoylu M. Orta əsrlərdə Azərbaycanda tərcümə sənəti. Bakı: Elm, 2000. 264 s. [на азербайджанском языке].

13. Azərbaycan Xalq Cumhuriyyəti / Parlament [Stenoqrafik hesabatlar]. Il cild, Bakı: Azərbaycan, 1998. 992 s. [на азербайджанском языке].

14. Шукуров Ш. История развития глагольных форм узбекского языка. Ташкент: Фан, 1966. 138 с. [на русском языке].

15. Cemiloğlu İ. XIV yy. Ait bir Kısası-Enbiya nüshası üzerinde sentaks incelemesi. Ankara: TDK, 2000. 271 s. [на турецком языке].

16. Paşazade A. Tevarihi-Ali-Osman. İstanbul: Gökkubbe, 2007. 517 s. [на турецком языке].

17. Nevai A. Mizanül-evzan. Ankara:TDK, 2015. 198 s. [на турецком языке].

18. Cəfərov N. Azərbaycan türkcəsinin milliləşməsi tarixi. Bakı: Bakı Universiteti, 1995. 208 s. [на азербайджанском языке].

19. Bergamalı K. Müesseretul-ulum. Ankara: TDK, 2002. 290 s. [на турецком языке].

20. Mirzəzadə H. Azərbaycan dilinin tarixi morfologiyası. Bakı: Azərtədrisnəşr, 1962. 370 s.

21. Kaşgarlı M. Divanu-lugat-it-türk. 4 ciltte. Çeviri: B. Atalay. Ankara:TDK, 2013. 230 s. [на турецком языке].

с Гасанлы-Гарибова Шабнам Расим кызы (hasanli-qaribova@mail.ru).

Журнал «Современная наука: актуальные проблемы теории и практики»

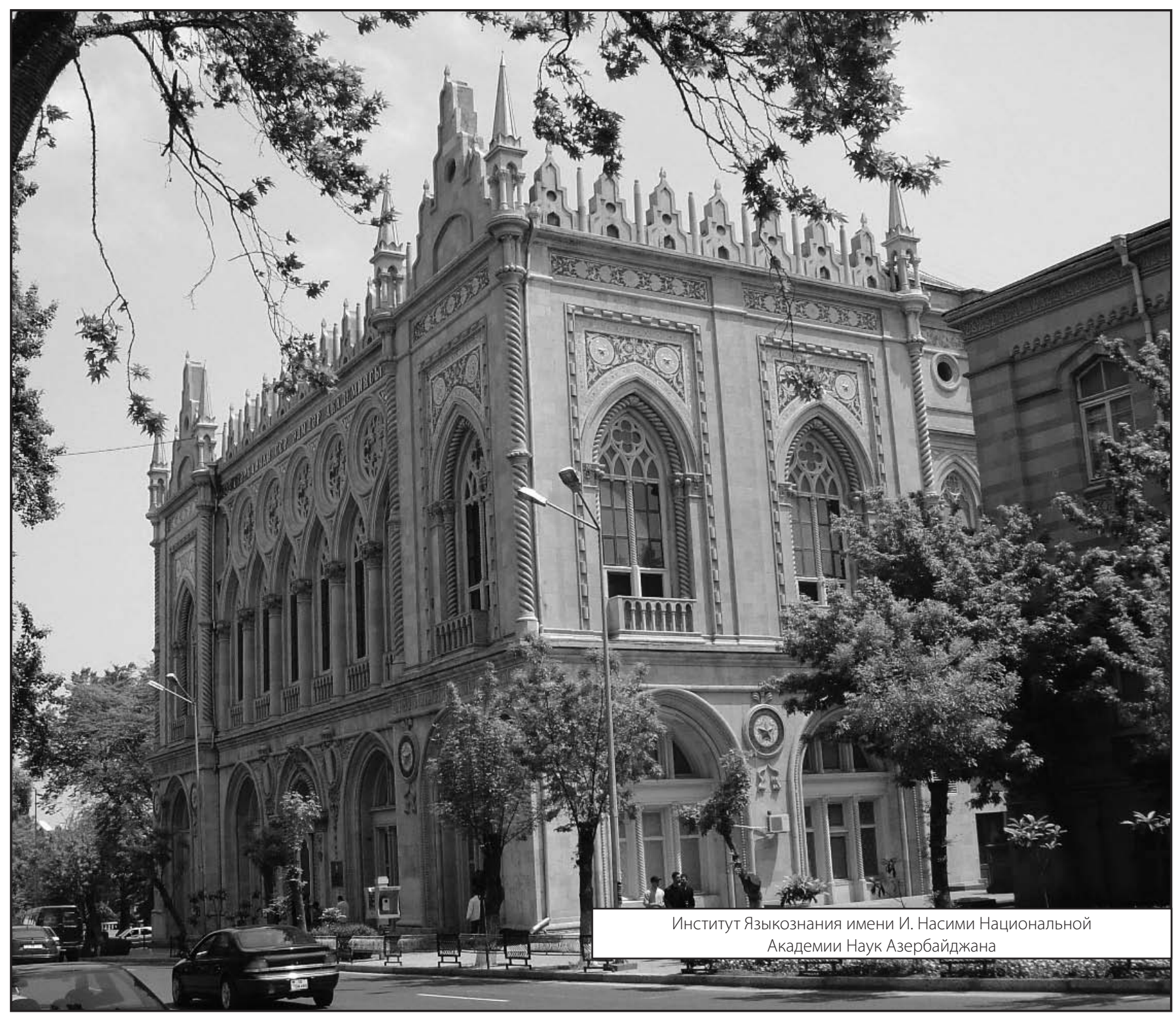

